\title{
Papers
}

\section{The quality of general dental care: public and users' perceptions}

\author{
Michael Calnan, Maria Dickinson, Graham Manley
}

\begin{abstract}
Background-Systematic evidence about how the public and users perceive and experience the quality of general dental care is in short supply, particularly in light of the recent changes in the general dental service. The study reported here attempted to fill this gap.

Objectives-To identify the criteria the public and users adopt in evaluating the quality of general dental care, and to identify the extent and nature of perceived concerns with general dental care.

Design-Postal questionnaires were sent to random samples of adults living in an inner city area (I) and semi-rural area (R) in southern England. Fifty six per cent (1499) in area $R$ and $48 \%$ (1388) in area $I$ completed the questionnaire after four mailings. Follow up face-to-face interviews were done with a purposive subsample $(n=50)$ of responders from the postal survey.
\end{abstract}

Main measures-Public/user views about quality of dental care were measured through groups of questions about the importance of and satisfaction with different aspects of dental care (access/ availability including cost; facilities; technical skills; and interpersonal care) and a scale (Dentsat) measuring general satisfaction was constructed from questions on different aspects of care.

Results-Evaluation of quality of general dental care from the users' point of view hinges on perceived technical skills, particularly pain management. Major dissatisfaction stems from concerns about costs of dental care and privatisation.

Conclusions-The criteria adopted by the public/users to assess general dental care are similar to other areas of health care, apart from the priority placed on technical skills and pain management. However, the major source of decline in satisfaction with the quality of general dental care is the barrier to access created by the rising cost of dental care and the increasing involvement of dentists in private practice. This evidence suggests that the public and users find the drift towards private practice and away from NHS practice a major source of concern.

(Quality in Health Care 1999;8:149-153)

Keywords: user views; satisfaction; quality of dental care

It has been argued that evaluations of quality of care should take into account the distinct perspective of the users as well as managerial and professional perspectives. ${ }^{1}$ A common method of eliciting users' views is through satisfaction surveys, although doubts have been expressed about the validity of the high levels of satisfaction which tend to be reported. ${ }^{2}$ Evidence from user satisfaction with dental care is no exception, ${ }^{34}$ although more recent evidence shows a decrease in satisfaction which has accelerated in recent years. In 1995 only 55\% reported being satisfied with general dental care, ${ }^{5}$ which is in contrast with other areas of the NHS where levels of satisfaction have remained about the same.

Studies have shown that users evaluated the quality of their dental care according to a range of criteria, particularly their dentist's interpersonal communication and technical skills. ${ }^{6}$ Anxiety and fear have long been considered to be a problem for dental care especially as an obstacle to attendance. ${ }^{7}$ Access and availability also appear to be fundamental aspects of satisfaction, ${ }^{8}$ and difficulties in gaining access may explain the decrease in satisfaction with dental care. This may be linked to recent changes in general dentistry, such as the withdrawal of funding in NHS dental care, the subsequent increase in dental charges, and lack of access to NHS dental care. ${ }^{9}$ One study reported that $35 \%$ of the population in Britain had experienced difficulty finding an NHS dentist in their area, ${ }^{10}$ most notably in regions such as southern England. ${ }^{11}$

Systematic evidence about how the public and users perceive and experience general dental care is in short supply in light of the recent changes in the general dental service. Our study attempted to fill this gap. More specifically, our objectives were to (a) identify the criteria that the public and users adopt to evaluate the quality of general dental care and (b) identify the extent and nature of perceived concerns with the quality of general dental care. 
Methods

The methodology involved a survey using structured postal questionnaires followed up by face-to-face interviews with a purposive subsample of those who returned the postal questionnaire.

POSTAL SURVEY

Postal questionnaires were sent to two random representative samples of the adult population (aged $\geqslant 18$ ) living in two areas of southern England-a semi-rural area (R) and an inner city area (I) - in 1996/7. The two samples were selected from the electoral register. Thirteen of the 365 wards in area R, and 18 of the 36 wards in area I were selected using computerised random numbers and a sampling ratio of approximately 1 in 28 . The samples of 3075 people from area $\mathrm{R}$ and 3001 from area I were then chosen at random proportionately from these wards. These samples were, however, reduced by excluding those who were found to be dead, had moved, or were too ill/disabled to complete the questionnaire. Thus, the sample in area $\mathrm{R}$ was reduced by 403 and in area I by 125 .

To explore public and users' views about quality of general dental care and the criteria used to evaluate dental care, the questionnaire contained groups of questions about dimensions of quality which have been shown in previous publications on users' views of health care, ${ }^{8}$ and specifically in studies of dental care, ${ }^{36}$ to be relevant - that is, access and availability (including affordability), physical environment (waiting area and dentists surgery), and technical skills and interpersonal care. The questions focused on satisfaction ratings with specific aspects of care on a five point scale or, alternatively, in response to a specific statement, from "strongly agree" through to "strongly disagree". In addition to satisfaction with performance, respondents were asked also to identify which of these aspects they particularly value or prioritise and also their complaints about dental care.

To measure overall satisfaction with dental care, a score (Dentsat) was calculated for each subject by adding together the scores of five Likert items - satisfaction with the dentists' manner, technical/dental skills, pain management skills, the cost of care, and access to care for a non-urgent visit. The higher the score the greater the satisfaction with dental care. The reliability of the scale was tested using Cronbach's $\alpha$ which ranges between 0 and 1 and indicates to what extent the items in an index are measuring the same thing. For example, if all respondents answered the same to all questions asked, $\alpha$ would be 1 ; but if all respondents answered completely differently, $\alpha$ would be 0 . Dentsat scores correlated highly with all its components, and it was found to be statistically reliable as a scale (reliability $\alpha$ : 0.74 area $\mathrm{R}$; and 0.88 in area I). The mean Dentsat score was 20.3 for both areas and SDs were 2.9 for area $\mathrm{R}$ and 3.1 for area I. In addition to these data, information was collected on the sociodemographic characteristics of the respondent-that is, age, sex, marital status, class, age at leaving school, ethnicity, housing tenure, overcrowding, and car ownership.

FOLLOW UP FACE-TO-FACE INTERVIEWS

The limitations of surveys of public/user views and particularly satisfaction surveys ${ }^{2}$ warranted a follow up using indepth face-to-face interviews with a purposive subsample of 50 respondents. This subsample was selected, at least in part, on the basis of respondents' scores on a scale measuring users' overall satisfaction with dental care (Dentsat). The aim was to identify respondents who were "polarised" in their perception and experiences of general dental care. Thus the purposive sample consisted of 20 selected at random from those with the top $10 \%$ of scores on the Dentsat scale, 20 from the bottom $10 \%$ of scores on the scale, and 10 who had not visited the dentist in the previous five years but did not have full dentures.

The interviews took place in the homes of informants by one of the investigators supported by a trained interviewer. The semistructured interview schedule was developed to examine people's views and experiences in greater depth, providing an opportunity to express their "lay" views in their own words and from their own perspective. The themes explored in these informal interviews followed the subject area of the structured questionnaire and included perceived dental health status, perception of dentists in general and their own dentist, and their evaluation of the dental care they had experienced. The interviewer specifically probed on what aspects of dental care were important and what influenced how they evaluated dental health care.

ANALYSIS

The data collected in the survey (with the exception of age and age left school) were either nominal or ordinal in nature and, in addition to descriptive statistics, bivariate analysis was calculated using non-parametric statistics. The interviews were tape recorded, transcribed, and the data content analysed. The study design aimed to use the qualitative data to complement the quantitative survey data so the two types of data are presented together.

The results begin by examining the criteria which the public and users adopt to evaluate dental care. This is explored through the aspects of quality of dental care that survey respondents assess as important and analysis of the interviewer's perceptions of what are the good and bad qualities of dentists and dental care. The second part of the analysis focuses on the more substantive questions about the level and nature of public/user "dissatisfaction" or concerns about general dental care, once again drawing on quantitative and qualitative data. The statistical analysis explores the relation between complaints and perceptions of quality of care.

A total of $56 \%$ (1499) in area $\mathrm{R}$ and $48 \%$ (1388) in area I completed the postal questionnaire after four mailings. The samples, when compared with their background populations, ${ }^{12}$ 
Table 1 Importance of different aspects of dental care

\begin{tabular}{lll}
\hline $\begin{array}{l}\text { Most important aspect of } \\
\text { dental care: (rank order) }\end{array}$ & $R ; \%$ (no of replies) & $\begin{array}{l}\text { I;\% (no of } \\
\text { replies = 978) }\end{array}$ \\
\hline Dentist's technical skills & $50(1148)$ & 48 \\
Availability (in emergency) & $21(1147)$ & 19 \\
Cost & $12(1148)$ & 16 \\
Dentist's manner & $9(1147)$ & 8 \\
Availability (non-urgent) & $6(1147)$ & 6 \\
Waiting times & $1(1147)$ & 1 \\
Dental staff's manner & $0.5(1146)$ & 1 \\
Dental surgery facilities & $0.5(1146)$ & 1 \\
\hline
\end{tabular}

showed no marked differences although the samples contained a slightly higher percentage of people who may be classed as affluent, those with a car, living in owner occupied homes, and in employment compared with the general population, and this difference was slightly more marked in area $\mathrm{R}$ than $\mathrm{I}$. Both samples contained a slightly higher number of people of pensionable age. The population in the two areas had markedly different sociodemographic profiles, particularly in relation to indicators of affluence and ethnic background, and thus it was necessary to analyse the data from the two areas separately.

From telephone interviews with a small sample of 50 of those in area $\mathrm{R}$ who did not respond to the survey, the main reason for non-response appeared to be the length of the questionnaire, lack of time, and a belief by a small group that it did not apply to them (for example, they had not been to the dentist for a long time or had worn dentures for many years).

In the second phase of the study, a total of 109 people were contacted to be involved in follow up interviews, of which 59 refused, the main reason being lack of time.

\section{Quality of dental care: users' criteria}

Respondents were asked to rank a list of different aspects of dental care according to importance (table 1). A dentist's technical skills were ranked by both samples as the most important aspect. This was evident among the interviewees when discussing how they evaluate dental care. For example, the informants from the most satisfied group referred to technical care when they were describing the positive qualities of their dentist:

"He's good. He does a good job, he knows what he's doing. He doesn't cause any problems."

"I think he's a very good dentist. I have known him for 35 years and generally I have got confidence in him, and when I go there, I get the feeling I'm going to a real professional."

The least satisfied informants also identified the dentist's poor technical skills, and a common complaint was that they were quick or rushed and were not thorough:

"You are in and out within two minutes flat and you do feel a little bit that maybe he hasn't been that thorough. He doesn't necessarily look at your teeth and give them a little clean or prod or whatever."

Some of those from the dissatisfied group did not feel they could evaluate their dentist's competence because either they had not seen their dentist for a long time or had not received much treatment, and thus could not form a judgment yet:

"Because we have never had any real problems it's difficult to tell how his skills are...I mean we've never had a filling with him or anything."

Furthermore, according to the interviews, most felt that a dentist had good dental skills if the patient experienced no problems with their dental treatment, as illustrated here:

"I mean if you have a filling and it falls out, or what she does, it doesn't cure you, then I think she is not a very good dentist."

These data illustrate the importance of the technical skills of the dentist. However, as table 2 shows, satisfaction rating with technical skills and with other aspects of dental care were high overall, apart from the cost of care where there was a marked level of dissatisfaction among both samples. Satisfaction with technical skills was explored in more detail in the survey (table 3), and the results show these specific questions identify slightly lower satisfaction with dental care, and indicate that infection control and ability to relieve dental problems have the highest levels of satisfaction, and pain management skills the lowest. The significance of pain management skills was evident from the interviews:

"He seems to be doing the right thing ...... I haven't had any pain."

\section{Sources of dissatisfaction with dental} care

Cost and its implications for the availability and accessibility of dental care was a major source of dissatisfaction in both samples. Thirty six per cent in area $\mathrm{R}$ and $40 \%$ in area I believed that the expense generally restricted how often they visited the dentist, and the main reasons cited for not attending the dentist in the past were having no dental problems $(27 \%$ in $\mathrm{R} ; 23 \%$ in I); difficulty paying for dental care ( $22 \%$ in $\mathrm{R} ; 18 \%$ in $\mathrm{I})$; fear of dentist ( $16 \%$ in $\mathrm{R}$; $15 \%$ in $\mathrm{I})$; reluctance to pay for dental care (14\% in R; $11 \%$ in I); and difficulty obtaining NHS treatment ( $12 \%$ in R; $9 \%$ in I).

Dissatisfaction with cost and access was also evident in the complaints. Seventeen per cent

Table 2 Satisfaction with different areas of dentist's care

\begin{tabular}{lll}
\hline Very or quite satisfied & $\begin{array}{l}R ; \% \text { (no of } \\
\text { responses) }\end{array}$ & $\begin{array}{l}\text { I;\% (no of } \\
\text { responses) }\end{array}$ \\
\hline Dentist's technical skills & $92(1264)$ & $92(1158)$ \\
Dentist's manner & $89(1257)$ & $90(1154)$ \\
Dentist's pain management skills & $90(1276)$ & $85(1148)$ \\
Receptionists & $82(1292)$ & $84(1154)$ \\
Dental nurse & $81(1286)$ & $88(1141)$ \\
Emergency care (subsample) & $79(172)$ & $81(133)$ \\
Cost of care & $33(1230)$ & $37(1074)$ \\
\hline
\end{tabular}

Table 3 Specific questions about dentist's skills

\begin{tabular}{lll}
\hline Agree or agree strongly that dentist: & $\begin{array}{l}R ; \% \text { (no of } \\
\text { responses) }\end{array}$ & $\begin{array}{l}I ; \% \text { (no of } \\
\text { responses }\end{array}$ \\
\hline Carries out infection control & $95(1232)$ & $93(1133)$ \\
$\quad$ precautions & $89(1235)$ & $93(1129)$ \\
Is able to relieve dental problems & $89(1243)$ & $90(1138)$ \\
Explains things well & $87(1197)$ & $83(1076)$ \\
Examines teeth thoroughly & $84(1225)$ & $86(1100)$ \\
Spends enough time & $80(1171)$ & $77(1013)$ \\
Gives enough information & $68(1213)$ & $62(1079)$ \\
Keeps pain to a minimum during & & \\
$\quad$ treatment & & \\
\hline
\end{tabular}


Table 4 Average Dentsat score by complaint

\begin{tabular}{llll}
\hline Complaint (SD) & $\begin{array}{l}\text { No complaint } \\
\text { (SD) }\end{array}$ & $\begin{array}{l}\text { Significance } \\
\text { (Mann- } \\
\text { Whitney test) }\end{array}$ \\
\hline Area R & $19.3(3.03)$ & $20.6(2.78)$ & $\mathrm{p}<0.001$ \\
Area I & $18.8(3.77)$ & $20.6(2.90)$ & $\mathrm{p}<0.001$ \\
\hline
\end{tabular}

in area $\mathrm{R}$ and $14 \%$ in area I said that they had a view about dental services in the past five years. Most (99\% area $\mathrm{R}$, data not available for area I) involved a complaint, of which $60 \%$ referred to a lack of access to dental services (mainly the unavailability of NHS dental care and high cost); followed by the dentist's care $(20 \%)$, which most felt to be unsatisfactory treatment.

Those who had reported a complaint about NHS dental services in previous years were statistically significantly more dissatisfied with their dental care (table 4). This might suggest that the major source of complaints about access and cost was also a major source of dissatisfaction with the quality of dental care as a whole. However, the differences in satisfaction scores between complainants and noncomplainants were not marked, suggesting that cost and accessibility are not necessarily the most important criteria for evaluating dental care.

Data gathered through the interviews identified the dentist's manner as the aspect of care most regularly referred to after the dentist's technical skills.

Firstly, the most satisfied group:

"He's very nice..... he talks to you and tells you what he is going to do and puts your mind at rest."

"He's a very nice bloke, you know very friendly, very helpful."

Secondly, a dissatisfied informant:

"I think his manner is terrible which is what put me off with the children, because he was very, well, he didn't talk, he doesn't tell you what he is doing or looking at."

The significance of the dentist's manner in users' evaluation of quality of dental care is illustrated by the results from a statistical analysis which examined the relations between general measures of satisfaction with dental care and specific aspects to identify which were the key elements in user evaluation of quality of dental care. Table 5 ranks statistical relations between specific aspects of dental care and overall satisfaction. In response to the overall question on general satisfaction with dental care, $50 \%$ were very satisfied and $41 \%$ satisfied with general dental care in area $\mathrm{R}$, with only

Table 5 Overall satisfaction with dental care correlated with specific satisfaction ratings

\begin{tabular}{lll}
\hline & $\begin{array}{l}\text { Area } R \\
\text { correlation } \\
\text { coefficient }\end{array}$ & $\begin{array}{l}\text { Area I } \\
\text { correlation } \\
\text { coefficient }\end{array}$ \\
\hline Ratings of satisfaction & $0.62^{\star}$ & $0.65^{\star}$ \\
\hline $\begin{array}{l}\text { Dentist's technical/dental skills } \\
\text { Dentist's manner }\end{array}$ & $0.60^{\star}$ & $0.63^{\star}$ \\
Management of pain & $0.57^{\star}$ & $0.62^{\star}$ \\
$\begin{array}{l}\text { Access to dentist for non-urgent } \\
\text { problem }\end{array}$ & $0.47^{\star}$ & $0.55^{\star}$ \\
Receptionist & $0.32^{\star}$ & $0.54^{\star}$ \\
Dental nurse & $0.31^{\star}$ & $0.57^{\star}$ \\
Cost of dental care & $0.29^{\star}$ & $0.34^{\star}$ \\
\hline
\end{tabular}

${ }^{\star}$ Correlation is significant at the 0.01 level (1-tailed).
Table 6 Relations between sociodemographic characteristics and satisfaction (Dentsat scores)

\begin{tabular}{lll}
\hline & $\begin{array}{l}\text { Area R mean } \\
\text { scores }\end{array}$ & $\begin{array}{l}\text { Area I mean } \\
\text { scores }\end{array}$ \\
\hline Age & $19.5(195)^{\star \star \star}$ & $19.6(240)^{\star \star \star}$ \\
$\quad<30$ & $20.0(242)$ & $20.2(217)$ \\
$30-39$ & $20.3(265)$ & $20.2(171)$ \\
$40-49$ & $20.8(207)$ & $20.8(152)$ \\
$50-59$ & $20.8(248)$ & $20.9(216)$ \\
$\quad 60+$ & $19.6(157)^{\star \star}$ & $19.7(242)^{\star \star}$ \\
Marital Status & $20.4(857)$ & $20.5(576)$ \\
$\quad$ Single & $20.4(69)$ & $20.2(100)$ \\
$\quad$ Married & $20.9(61)$ & $21.3(53)$ \\
$\quad$ Divorced/Sep & $20.4(1124)^{\star}$ & $20.5(880)^{\star \star \star}$ \\
$\quad$ Widowed & $19.0(23)$ & $18.8(94)$ \\
Ethnic Background & & \\
$\quad$ White & $20.7(436)^{\star \star \star}$ & $20.7(316)^{\star}$ \\
$\quad$ Non-white & $20.1(679)$ & $20.2(628)$ \\
Crowding & & \\
$\quad$ Overcrowded & Not overcrowded &
\end{tabular}

${ }^{\star} \mathrm{pP}<.05{ }^{\star \star} \mathrm{p}<.01{ }^{\star \star \star} \mathrm{p}<.001$. Standard one way ANOVA.

$3 \%$ reporting some degree of dissatisfaction. In Area I the respective figures were $45 \%$ for both very satisfied and satisfied, and once again 3\% reported some degree of dissatisfaction. This table also shows that the strongest influences on general satisfaction are the dentist's technical skills, including the management of pain, and the dentist's manner. Cost of dental care has a much weaker statistical relation with general measures.

\section{Sociodemographic characteristics and Dentsat scores}

There was some evidence of variations in satisfaction scores by social position (table 6). Older people, those who were widowed, and those from a white ethnic background were significantly more likely to be satisfied with the dental care they received according to Dentsat scores. No consistent pattern existed of relations between indicators of affluence/ deprivation and satisfaction, apart from with the measure of overcrowding.

\section{Discussion}

The aim of this study was to explore, in the light of recent changes in dentistry and the evident shift away from NHS dentistry towards private dentistry, how users evaluate the quality of dental care provided. The results showed that the criteria used to evaluate general dental care are various, but the most important appeared to be the dentist's technical skills, specifically the dentist's management of pain. Dissatisfaction stems mainly from concerns about costs of dental care and privatisation. Caution must be expressed about the generalisability of the results, particularly those from the inner city area where the survey response rate was low and they may under represent those who might be critical of dental care.

The key aspects of quality of dental care from the users' perspective according to the evidence collected in this study was dentists' technical skills, access and availability, and dentists' manner and interpersonal care. More specifically, the most important element of quality found in both the survey and qualitative data were dentists' technical skills. Technical skills for the user seemed to involve the ability 
to relieve dental problems, spending enough time doing a full examination and treating the problem thoroughly, and to be able to minimise pain. Overall levels of satisfaction with technical skills were high, although this may be artefact of the methodology and the sample in that it was skewed towards the elderly who tend to report higher levels of satisfaction. ${ }^{8}$ Questions of a more specific nature elicited greater dissatisfaction with dental care. For example, around $90 \%$ were satisfied with their dentist's pain management skills, yet only around $70 \%$ felt their dentist kept pain to a minimum during treatment.

The fear of pain and pain management are key elements in users' evaluation of quality, although this does not explain why, according to data from national surveys, ${ }^{5}$ there has been a deterioration in satisfaction with general dental care as a whole. Clearly, users were concerned with barriers to accessibility created by the perceived lack of access to NHS care and the concern about the cost of care. The fact that cost was seen as a barrier to care and the evidence that emergency dental care was deemed as the second most important aspect of dental care illustrates the importance of access and availability to users of care. The importance of gaining access to emergency care may reflect the fact that users are increasingly reluctant to attend the dentist for reasons other than to relieve dental problems (pain and discomfort) because of perceived costs of care. Hence, the need for access to emergency care for treatment of problems rather than the need for access to routine preventive care.

Clearly then, current dissatisfaction with dental care is rooted in perceived problems of access. Once the dental care is accessed, however, users evaluate their dental care in terms of both the dentist's technical skills and the dentist's interpersonal care (manner and communication). Research in general practice has consistently reported that users place as much importance on the style and interpersonal care of their general practitioner as they do on their technical skills. ${ }^{12}{ }^{13}$ There are parallels in general dental care despite the fact that general medical practice deals with a more diffuse set of problems with less technical orientation. The evidence confirms the theory, however, that there are some criteria such as interpersonal care which are common in users' evaluation of quality, irrespective of the type of health care being provided, and some which are specific to that service..$^{814}$

Finally, the age gradient in relation to satisfaction with dental care parallels evidence from previous research into dentistry and other areas of health care. ${ }^{812}$ The finding that those who were widowed were also more satisfied may be an artefact of the relationship with age. There was little consistent evidence of a link between deprivation and satisfaction, which is surprising given the perceived importance of cost as a barrier to dental care. However, the measure of general dental satisfaction does focus on users' specific experience of dental care which tends to emphasise the behaviour of the dentist.

In conclusion, evaluation of quality of dental care from the users point of view according to the evidence presented here hinges on the perceived technical skills, particularly pain management, of the dentist. Major dissatisfaction with general dental care as a whole stems from concerns about the cost of dental care and privatisation, but once users access dental care, concern about cost is replaced by concern about the dentist's interpersonal care. This evidence suggests that the public and users find the drift towards private practice and away from NHS practice a major concern. ${ }^{11}$

Thanks to Dr S Almond for statistical advice. The study was funded by a grant from the NHS Executive South East Project Grant Scheme.

1 Ovretveit J. Evaluating health interventions. Milton Keynes, Open University Press, 1998.

2 Williams B. Satisfaction: a valid concept? Social Science and Medicine 1994;38:509-16.

3 Kress GC, Silversin C. The role of dental practice characteristics in patient satisfaction. General Dentistry 1987;35:454-7.

4 Robinson P, Croucher R. The satisfaction of men with HIV infection attending a dedicated dental clinic: a controlled study. Aids Care 1994;6:39-48.

5 Bryson C. Trends in attitude to health care:1983 to 1995. A report for the Department of Health based on results from SCPR's British social attitude surveys. London: Social and Community Planning Research, 1996.

6 Gerbert B, Bleecker T, Saub E. Dentists and the patients who love them: professional and patient views of dentistry. who love them: professional

7 Corah NL. Assessment, reduction and increasing patient satisfaction. Dental Clinics of North America 1998;32:77990

8 Williams SJ, Calnan MW. Convergence and divergence: assessing criteria of consumer satisfaction across general practice, dental and hospital care. Soc Sci Med 1991;33: 707-16.

9 Rhodes J, Gregory S. Biting the bullet: what drove dentistry into the private sector. Health Service fournal 1995;105:2022 .

10 British Dental Association. One in three claim difficulty in finding an NHS dentist locally. London: BDA, 1996.

11 Silvester S, Calnan M, Manley G, et al. Public or private? Dental practitioners' beliefs, values and practices. Canterbury: University of Kent, 1998

12 Dickinson M, Calnan M, Manley G. Voice and choice in general dental care: final report to NHS Executive South East. Canterbury: University of Kent, 1998

13 Calnan M, Coyle J, Williams S. Changing perceptions of general practitioner care. Eur f Pub Health 1994;4:108-14. 14 Sitzia J, Wood W. Patient satisfaction: a review of issues and concepts. Social Science and Medicine 1997;45:1829-43. 